\title{
Innovating Business Activities Using Triple Bottom Line Concept: The Case Of Building Hygene Company Valtex

\author{
Melita Balas Rant, University of Ljubljana, Slovenia
}

\begin{abstract}
Valtex, a Slovene company that provides hygiene products for commercial buildings, up until recently operated successfully in the eyes of the CEO and owner Niko Kumar, meeting the expected growth, profit, and cash flow. Yet suddenly the company is faced with the threat of bankruptcy which put past success on shaky grounds. Niko Kumar, together with his business partner and sales consultant, is forced to think deeper about the real value of the "building hygiene" business, its attractiveness in terms of triple bottom line (profitability, planet, and people), and study the value - if any - Valtex really creates for customers and society (planet and people). Most importantly with bankruptcy at the horizon, Niko is forced to explore novel areas where Valtex would really create substantial value for the customer and society. The case is suitable for post graduate students of management, short duration executive education programs, executive MBA programs, and entrepreneurship education. When discussing this case with a goal of helping Niko Kumar to innovate novel business activities for Valtex using sustainability perspective, an instructor is advised to use a set of strategic concepts: Porter's (1985) five-force analysis and company activity system, Brandenburger and Stuart's (1996) concept of value adding activities, Elkington's (2002) concept of triple bottom line as well as train students in using brainstorming and other creative thinking techniques.
\end{abstract}

Keywords: Industry Analysis; Activity Analysis; Competitive Advantage; Sustainability; Triple Bottom Line; Innovation; Business Model

\section{INTRODUCTION: FINDING BEACONS OF HOPE IN A DARKENING LANDSCAPE}

"How do we avoid the threat of liquidity problems, and how could our business model be changed?"

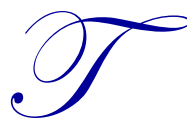

his was the question ringing in the head of Niko Kumar, CEO of Valtex, a 21-employee venture operating in the Professional Building Hygiene industry in Slovenia. At the beginning of February 2010, Niko felt that his ever-present stamina for his business was being suppressed by the constant struggle to maintain liquidity - a battle he had been pushed into over the previous couple of months. Although the global economic downturn of 2008 onwards had "crashed" many companies, Valtex had not felt any significant impact until now. In fact, Valtex revenues had increased steadily throughout 2009, albeit with a growth rate just one third of previous levels: in 2008 revenues had grown by $21 \%$, while in 2009 they were up by $7 \%$.

Recently Niko had often asked himself why he had been convinced that Valtex would escape the crisis. Somehow, he had found an explanation in Avian flue, the fear of which had been widespread in the summer of 2009 , boosting consumption of hygiene and disinfection products. But over the last couple of months revenues had fallen by a staggering $30 \%$, with liquidity challenges surfacing shortly afterwards. To pay his employees' salaries, and to settle the accounts receivable for the two strategic suppliers on whom Valtex depended for the supply of its products, Niko spent most of his waking hours scratching around for money and securing liquidity loans from banks. After three months of this he could barely see any sense in running the business any longer, unless a viable, prosperous, and meaningful solution could somehow be found. 
In the search for such a solution he met frequently with his closest business companion, Tomaž Zaletel, coowner of Valtex and its purchasing director, and Aleš Planina, an external consultant for sales. They summarised the situation as follows: "Over the years Valtex's growth has been self-evident; lately this has not been the case. Our lives have changed for the worse. Companies in all industries are cutting costs, and in consequence are buying fewer hygiene products. Some are laying people off - and so consumption of hygiene products is falling even more. This means less business for us, less revenue, and more problems. Our business has experienced an earthquake, and now we feel like we are in a fog: it no longer gives any of us any joy, and there are lots of dull faces around the company. We feel lost and directionless: but what is the right path for Valtex? What moves should we make? We have been thinking about these questions a lot, but making sense out of the mess isn't easy. Are we facing troubles only because of the global downturn? If this is the case, how long is it likely to last? Is our business properly designed for a lasting recession? Should we adapt? What should we change? How? We need to navigate through these dilemmas and find a way out."

\section{THE PROFESSIONAL BUILDING HYGIENE BUSINESS}

Valtex operates in the Professional Building Hygiene business, providing products and services for the maintenance of cleanliness and hygiene in buildings in the "out of home" sector.

\section{Product Categories}

There are several product categories through which the professional building hygiene industry is sustained: hygienic paper products (paper towels, toilet paper, napkins, paper tablecloths, and mats); soaps (in hard, liquid, foam forms; industrial soaps, disinfection soaps); paper and soap dispensers; (this category also includes toilet brushes, bins, etc.); products for cleaning (powders, liquids, extractors, softeners, and the like); and cleaning utilities (trolleys for cleaning products, sponges, gloves, brooms, cleaning machines, and so forth). Experts mostly divide the professional building hygiene industry into two distinct major groups: hygiene products (hygienic paper products, soaps) and hygiene equipment (chemical products for cleaning and cleaning utilities). The usual abbreviation is HPE (i.e., hygiene products and equipment).

\section{Customer Segments}

Due to differences in the factors driving purchasing decisions, hygiene products and equipment offerings vary across customer segments. For instance, hospitals and schools pay more attention to price and are willing to subordinate the quality aspect of the offer, while HoReCa (hotels, restaurants, and catering) companies pay more attention to quality and aesthetics. Experts differentiate between the education sector (schools, faculties), the health sector (hospitals, clinics), the touristic sector (hotels, restaurants, and catering), the industrial sector (manufactories and business buildings), the trade sector (shopping centers), and the service sector (cleaning services). In addition to material products, companies competing in professional building hygiene also offer a range of supplementary services. They provide consulting on the development of efficient hygiene systems for clients' buildings, educate clients on how to maintain hygiene in buildings effectively; offer assembly and maintenance of client's hygiene equipment, while some of them also provide cleaning services directly.

\section{Fragmentation of the Industry}

The professional building hygiene industry is split between producers of HPE and providers of HPE. Producers of HPE are usually global MNCs (Kimberly Clark, Georgia Pacific, Lucart Group, SCA), vertically integrated backwards into forestry products and the paper industry. Due to their direct exposure to the issues of woodland depletion and biodiversity impact, HPE producers were among the first to adopt sustainability thinking and action. In order to raise their product above the commodity level, producers of HPE also invest a lot into marketing and brand development.

Producers of HPE rarely sell their products directly; usually, they outsource selling activities to local companies (HPE providers). These local companies are culturally and institutionally better adjusted to specific geographies and are hence much more effective sellers than the MNCs would be. Local companies sign a contract 
with a MNC for the sales of a specific product brand. In one region, two different local providers can be found representing two different brands of the same MNC, positioned in different customer and price segments.

In the HPE sector, hygiene paper is the highest velocity FMCM (Fast Moving Consumer Good) and the main driver of revenues. For the average HPE provider, sales of hygiene paper account for $70 \%$ of revenues, while $30 \%$ come from sales of soaps and cleaning products. In consequence, all HPE providers offer hygiene paper, while being much more selective on providing other HPE products. If a specific HPE provider's range does not match client expectations, it will collaborate with another HPE provider to meet these client demands.

The established business model is that dispensers are given to clients free of charge, in return for committed purchases of hygiene products (paper and soaps) from a specific HPE. The HPE providers hence design their business to a "razor-blade" business model (Tripsas \& Gavetti, 2000), where the dispensers presents the razor the platform for revenue creation - while the hygiene products present the blade part of the business model - the revenue stream and profit driver.

Providers of HPE treat each dispenser given to a client as a consumption unit. The more active consumption units the HPE provider holds, the greater the consumption of the hygiene products, and the higher the stream of revenues. In the analysis of revenue drivers, HPE providers differentiate strictly between users and buyers. Owners or tenants of the building are buyers (referred also as clients): buyers are consumption- and cost-sensitive. Users however are not consumption- and cost-sensitive; their consumption of hygiene product is less rational than at home. Different types of users - employees, regular guests, and irregular guests - can exhibit irrational behaviors to different extents. On average, employees are the most hygiene sensitive, while irregular guests are the least hygiene sensitive. Due to users' tendency for overconsumption, the design of hygiene equipment for public places plays an important role for the buyer, who in his purchasing decisions pays attention to the costs of hygiene products use.

\section{Dispensers}

Dispensers are mechanisms for the hygienic and economically efficient usage of hygiene paper, towels, and soaps. They represent an investment in the buyer's hygiene system infrastructure with an expectation of creating the steady stream of future revenues through the sale of hygiene paper products and soaps. Due to buyers' concerns with costs, over the past decades producers of HPE have committed considerable attention to designing dispensers that account for "away from home" user behaviours. Development of products with user behavior in mind led to the design of many sorts and formats of precut paper towels (i.e., folded paper towels) and jumbo sized toilet paper between 1930 and 1960. Automatic dispensers were developed in the 1970's, which cut paper towels into smaller pieces and dispensed them "one by one" to limit the tendency for over-consumption of towels by users. Soon automatic dispensers became the dominant solution for handling "away from home" behaviors.

However, as the money does not lie in the dispensers, but in the rapid consumption of hygiene products, the challenge for HPE producers was how to lock buyers into purchases of designated hygiene products. To that end, HPE producers have designed branded dispensers that work only if the same-brand hygiene products are used. Lockin systems and product differentiation through branding soon became the rule of the competitive game in the professional building hygiene business. The latest dispensers are fully electronically controlled, allowing building owners to control consumption per dispenser and therefore to control "cost in use" of hygiene products (paper, soaps).

\section{Hygiene Products}

Hygiene products include paper, soaps, and cleaning liquids with paper being the most important revenue driver ( $70 \%$ of revenues) and its costs being the most important determinant of the profit. The costs of hygiene paper are determined by the costs of inputs and production processes.

Inputs

Hygiene paper is made of pulp, a commodity traded on global stock exchanges (SE). The dynamics of pulp prices on global SEs are determined by current stocks of pulp, GDP growth rates and their distribution across 
economies, prices of crude oil, and the under- or over-capacity of pulp plants. Pulp supply is limited to no more than 3-4 months of demand; longer storage periods generate warehouse space problems. Pulp production drives deforestation, which presents a great burden for the environment alongside negative externalities in the form of biodiversity loss, land erosion, carbon emissions, and so forth. Costs and prices of hygiene paper correlate closely with the prices of pulp. However, they also depend on the type of pulp used in production. In general, hygiene paper can be produced from three types of pulp: virgin pulp, recycled pulp, or regenerated pulp, or with a mixture of the three. The input for virgin pulp is wood; the inputs for recycled pulp are paper and cardboard; the input for regenerated pulp is high quality magazines. In the process of the production of regenerated pulp, low-quality fibers are removed out of the recycled material.

\section{Production Process}

In the paper production process, wood is first broken down into cellulose, which is then fed into water boilers in the paper mills (Blum, 1996). Water and pulp is mixed in a 1:99 ratio and adhesives, fabric softeners, fragrances, and colors are added. This substance is boiled at $450^{\circ} \mathrm{C}$ and then pushed through a paper-making machine at speeds of more than $100 \mathrm{~km} / \mathrm{hour}$, the output of which is wound onto a "mother reel." These mother reels are in subsequent stages cut into smaller reels, according to the specifications given by customers. Customers are specialized factories producing the final paper products; e.g., hygiene paper, and are called paper converters.

\section{Cost Structure}

The cost of the final paper product is determined by input costs and the complexity of the production process. Virgin pulp has the most expensive input, wood; however, the process of transformation is the simplest. In sum, the total costs of hygiene paper production made from virgin pulp are the highest, corresponding also to the highest quality of paper. The quality of the hygiene paper is measured by its functionality (absorption capacity, wet strength, cleanliness measured by number of spore-forming bacteria, and molds per square) and aesthetics (appearance, odor, color, touch). On average, the total cost of hygiene paper made from virgin pulp is 35\% higher than the cost of hygiene paper made from recycled pulp. The inputs of recycled hygiene paper are substantially cheaper than wood (120\$ vs $600 \$$ per metric ton), so regardless of its more complicated production process, the total production cost (depreciation, labor, material) amounts to only $2 / 3$ that of virgin hygiene paper. However, the quality of the recycled hygiene paper is lower both in terms of functionality and aesthetics. Nonetheless, the quality can be improved if low-quality fibers are removed, which creates a $22 \%$ average extra cost. This, so called regenerated, hygiene paper has superior functionality, yet aesthetically is still inferior. Quality can be further improved by adding extra layers of paper, improving the grammage of the paper, improving its relief structure, adding chemicals to enhance absorption capacity, and so forth, but all these improvement processes add substantial costs. Ability to lower costs and prices is key to the competitive battles in this industry.

\section{Competitive Dynamics}

The professional building hygiene industry is mature, oligopolistic, and closed in nature, characterized by a substantial number of differentiated competitors and low profit margins. The most squeezed of the players in this competitive game are the small HPE providers. In general, sales of HPE positively correlate with GDP. The profit margins achieved by HPE providers are determined by a combination of purchasing prices, quality of brand, and workforce efficiency. The unattractiveness of operating with thin profit margins is improved by the fact that HPE providers are in a repeated-sales model of business, where customer loyalty is a valuable asset.

\section{Buyers' Behavior}

Buyers of hygiene products aim to maximize user experience with the lowest cost possible. When tradingoff between these two divergent goals, they consider many criteria such as price, functionality, hygiene, aesthetics, ecology, replacement cost of the HPE provider, contract termination flexibility, delivery conditions, completeness of product and service range, after-sales services, quality of advice, quality of brand, credibility and reputation of HPE provider, discounts and payment requirements, etc.. The assigned weights to these different purchasing factors differ across customer segments. For instance, hospitals pay more attention to hygiene factors, while HoReCa clients put more attention on aesthetics. When choosing between different offers, buyers are exposed to a computational 
challenge akin to comparing apples and pears. For instance, a $10 \%$ lower price for paper towels does not necessarily lead to a $10 \%$ lower cost: towel consumption is determined by the quality of the towel (i.e., absorption, aesthetics) together with the quality of the dispenser. This blurs the possibilities for straight comparison between different offers; and hence consultancy, personal impressions and the reputation of the HPE providers all play an important role in convincing the buyer.

\section{THE PROFESSIONAL BUILDING HYGIENE INDUSTRY IN SLOVENIA}

Nowadays in Slovenia there are five "big" HPE companies: Company B, Company K, Company EE, Company E (the capital letters are the first letter of company name), and Valtex. All of them are basically distributors of products of major multinationals like Georgia-Pacific, Kimberly-Clark, SCA, Ecolab, and similar, though some also possess their own brands and production facilities. Regardless of that, they can be treated as standard HPE providers, since their revenues mainly depend on the sales of hygiene products imported from global HPE producers. In general, these global producers do not pay much attention to requests coming from Slovenia: Slovenian partners are too small to have an impact on MNCs sales policies (pricing, marketing, payment settlements, the size of minimum stock keeping units (SKUs), etc.). This domination of the Slovenian professional building hygiene industry by five companies has developed gradually over many years.

\section{Before 1991}

scrubs.

Only a few artisanal workshops produced or imported equipment for professional building hygiene, mostly

\section{1-1998}

Slovenia became an independent market economy that caused an outburst of entrepreneurial activity seeking profits where supply lagged demand, not least in professional building hygiene. There was unarticulated demand for hygiene products which the established (collectively owned) companies could not successfully meet. The initial entrepreneurial ventures served mainly as mediators, importing hygiene products (paper products, soaps, and sanitation kits) from abroad and selling it to industrial and public sector customers more competitively than Paloma (Slovenian HPE producer). Buyers - mainly newly privatized companies from industrial sectors which were paying attention to the efficiency of their cleaning operations - were eager to replace simple paper rolls with more elaborate solutions. HPE providers that were able to gain new clients faster, grew faster. In this early "Land Grab" competition among the early HPE providers, the key success factor was a capacity to self-organize sales activities efficiently. The most successful company in the "land grab" was Company K, once part of Metalka (Koper), which had been selling Scott and Company EE Georgia-Pacific/Ultimatic products. However, between 1993-1999 a number of new companies (Valtex, Company S, Company B, Company E, and Company $\mathrm{V}^{1}$ ) started taking significant market share. In the face of raising competition, offers diversified and the battle for customers intensified. At the same time, many new business opportunities arose as a greater number of customers outsourced their professional building hygiene requirements to cleaning service companies. To win new clients, merely offering high quality cleaning products proved insufficient. New customers were won through reducing prices and demonstrating product knowledge. Companies also began to offer dispensers freely, viewing it as an investment in their client base.

\section{8-2008}

Cleaning services providers became major players, stepping into the shoes of both competitors and customers to HPE providers. Cleaning services further segmented the industry by introducing one more layer between clients/buyers of HPE (e.g., schools, hospitals, companies, etc.) and providers of HPE (e.g., Valtex, Company K, Company S, Company B, Company E, and Company V). Cleaning services normally signed contracts with a client for a fixed price (revenue) per hour of cleaning service per square meter of building. The contracted fee accounted for the average usage of hygienic products (paper, soaps, and cleaners), the expense of cleaning services,

\footnotetext{
${ }^{1}$ Competitors are presented by the first letter only due to the fact that some information about their business strengths and weakness are subjective interpretations of top management of Valtex and may be disputable by them.
} 
and the revenues of HPE. In this way cleaning companies' clients outsourced the purchase of cleaning chemicals, equipment and hygiene paper. While usage of cleaning chemicals could be easily estimated by the size of the cleaning area $x$ frequency of cleaning (i.e., 20 days per month), paper use is a very different story: usage (and cost) is determined by the number, frequency, and behaviour of toilet visitors. Cleaning companies did not pay much attention to this due to the high revenues they were making in the early years of the practice, but by the end of 2009 revenues had dropped (following the entry of a large number of new small and adaptive cleaning companies to the market), while the practice of outsourcing purchasing of hygiene paper had become a "rule." The cleaning companies began to put huge pressure on hygiene paper suppliers to reduce their prices.

In fear of being squeezed out, some HPE providers - among them Valtex - devised collaborative win-win strategies with cleaning services firms. For instance, in order to keep the business and remain the preferred distributor to a major cleaning service company, HPE providers offered free delivery of all hygiene products (hygiene papers, soaps, etc.) directly to buildings, while equipping them with free dispensers. In consequence, those cleaning services companies that had begun to collaborate with HPE providers gained some incremental cost advantage over their non-collaborative competition. Substantial synergies were created also for the HPE providers, since serving new cleaning service firms also gave access to their clients. This resulted in fast expansion of HPE distribution networks with little investment in sales processes, sales of larger quantities, and an ability to compete at lower levels of margin. In consequence, HPE segments consolidated as the bigger squeezed out the smaller.

\section{By the End of 2009}

The industry has consolidated, with five main HPE providers dominating the Slovenian market by the end of 2009. Alongside Valtex (19.1\% market share), these will be called Company B (18.4\% market share), Company EE (23.5\% market share), Company K (17.8\% market share), and Company E (20.8\% market share) All are relatively small businesses with 15-20 people, and all of them entered the business in the early 1990s, either transitioning to it from other industrial segments (e.g., paper industry, chemical industry) or starting from scratch as entrepreneurial startups. Over years of competitive pressure, the differences between them have been reduced to the minimum. When one competitor has made a good competitive move (i.e., introducing consultative selling), the others soon followed. Habitually, they compete for the same customers. When bidding for the same (public) customer, transparency is required and hence imitation is fast and efficient. There is however some knowledge that can stay hidden. All of them treat customers with product consultative approaches; the major differences relate to the brands and MNCs they represent. However, despite these many similarities, there are still some business and performance differences (see Figure 1).

Company B is a family run business of 19 employees set up in 1993. They sell mainly hygiene products from Kimbery Clarke (USA), including Kleenex, Scott, and Kimberly Clarke professional. In the early 1990's Company B worked as a re-seller of hygiene products and equipment supplied by Valtex and Company K. In the late 1990's Company B set up its own direct supply pipeline from Kimberly Clarke, and soon started to develop its own sales force capabilities. The primary focus today is on the not-for-profit sector. They were the first in Slovenia to offer a complete range of products and services for professional building hygiene (hygiene paper products, soaps, cleaning products, dispenser's brooms, bags, baskets, etc.). In the period from 2006-2007, Company B underwent some family disputes, which were successfully resolved in 2008, leading to better organizational design and an increased market share. When securing new customers they have on average lower prices than competitors, along with a highly personalized approach to clients.

Company K was set up in early 1990's, as a spin-off from Metalka (Koper), selling products of Scott, Company EE, and Georgia-Pacific/Ultimatic. In later years it focused mainly on the sales of Kimberly Clark (USA) products. Company $\mathrm{K}$ has higher employee productivity than Company B and Valtex due to a slightly different business model design; its sales-force is externalized in the form of self-employed sales reps, while larger key accounts are managed internally. Company $\mathrm{K}$ mainly targets the private sector (75\% of revenues) and hence provides mainly selected (higher margin) products and services (Public Reporting System of Commission for the Prevention of Corruption, 2012). Their competitive advantage lies in a strong brand, well recognized in Slovenia, which allows them to compete with higher profit margin. Though Company $\mathrm{K}$ holds $20 \%$ of market share by value (revenue), in volume terms its share is just $11 \%$. Due to its higher pricing position, the company experienced a slight drop in revenues and operating profit in 2009; however its high ROS margin was preserved. 


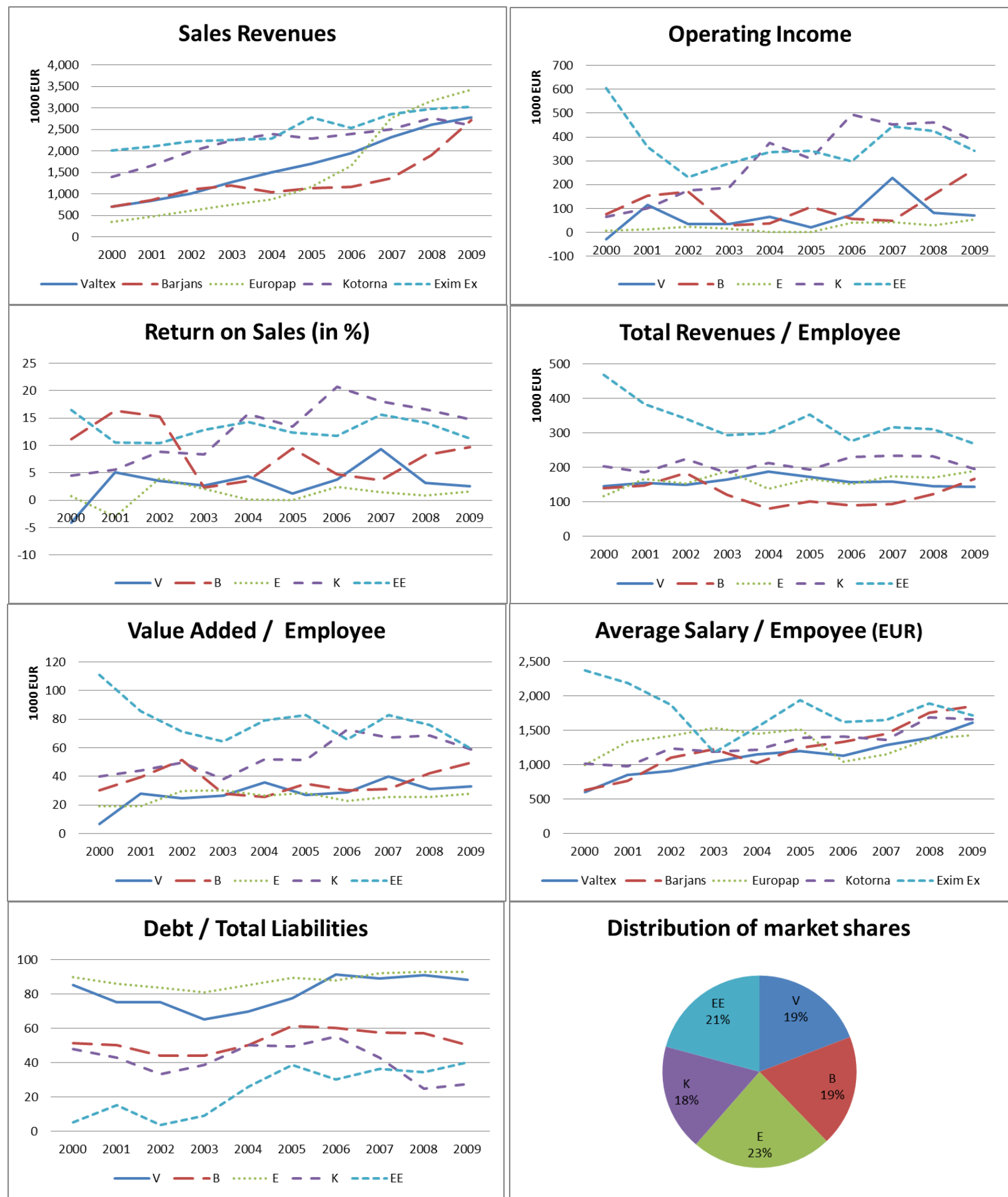

Figure 1: Comparative Analysis of Performance Differences of Main HPE Providers in Slovenia in the Period 2000-2009 Source: Company Valtex, B, E, K, EE (Financial Reports of Slovenian Companies, 2012)

Company EE was set up in 1991, selling mainly Ultimatic, a brand produced by Georgia Pacific. They follow a business design similar to Company $\mathrm{K}$, covering major accounts with an internal sales force, while outsourcing the rest to self-employed sales reps. Early on they secured some major customers (e.g., Krka, Slovenian pharmaceutical company) and schools, which created a first mover advantage. In 2000-2001, Company EE designed 
its own brand of hygiene products (paper, soaps) and equipment (dispensers), with production of hygiene paper and dispensers outsourced to Metsa: the company also integrated backwards into the production of soaps and paper towels, two of the highest turnover segments. In 2008, the company was sold; the new owners did not however change the business design in any substantial manner. In general, Company EE is focused on the private sector, where it competes with a highly reputable brand (Ultimatic) and "not too high" pricing. Substantial revenues are also generated through export, selling mainly own brand products to wholesalers abroad.

Company E was set up in 1997, offering hygiene products and equipment branded with Tork, a brand produced by SCA (Sweden). Initially they targeted the not-for-profit sector, and then gradually transitioned to the private sector, investing substantially in its own professional sales force. In 2006 they acquired a minor Slovenian company, specializing in the production of cleaning products. Late in 2009 the company considered investing in a facility for the production of hygiene paper. Competing with extremely low prices, their ROS margin is the lowest in the industry. They employ a considerable amount of debt financing, and their Debt/Total Liabilities ratio is higher than that of Company EE, Company B, and Company K.

\section{VALTEX}

Valtex (Valtex Company Profile, 2012) was set up in 1993 by two 20-year old entrepreneurs, Niko Kumar (CEO) and Tomaž Zaletel (purchasing director). They initially had no knowledge of sales, distribution, purchasing, finance, accounting, or operations - nor experience of the hygiene industry. The coincidence of two events in the same week - coming across dirty toilets in a yachting marina, and watching a movie where actors used paper wraps to cover dirty toilet frameworks - sparked the idea of selling such wraps to yachting marinas. They immediately signed a contract with the Italian company producing the wraps (and other related paper products for public toilets) and started to sell them vigorously across Slovenia. Also, they grasped fast that to survive they needed to expand their trade to encompass the complete range of hygiene products. Their personalized approach helped them to win their first major accounts. They grew quickly and a decade later, in 2004 and 2005, Valtex qualified as a "Gazelle" company, a listing developed by Slovenian newspaper Dnevnik to celebrate local fast-growth businesses (see Figure 2).

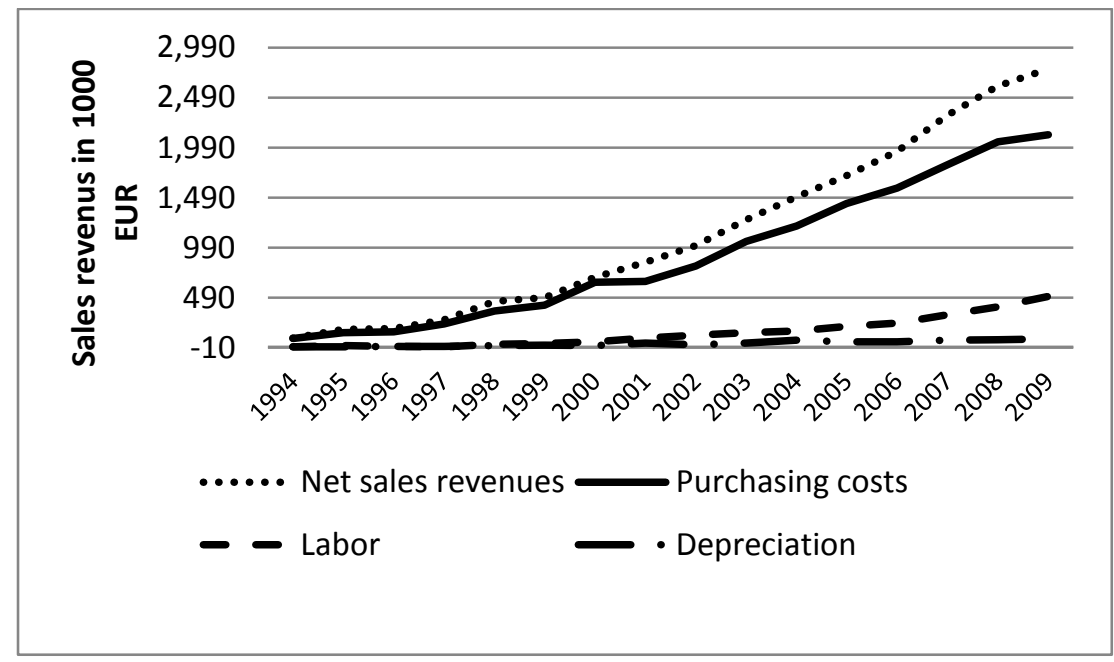

Figure 2: Growth of Valtex's Sales Revenues and Cost in the Period 1994-2009 Source: Company Valtex (Financial Reports of Slovenian Companies, 2012)

\section{Character and Roles}

In character and roles, Niko and Tomaž complemented each other. Niko was an innovator by heart, dedicating his spare time to computing and modelling: he took the role of CEO, and constantly chased new deals and ideas. Tomaž on the other hand, more disciplined and organized by nature, coordinated the operational aspects of the company. In the process of optimizing operations and information flows, Tomaž first organized the invoicing 
process by allocating each dispenser as a separate cost center. Dispensers were soon treated as gifts/investments to clients in case the latter agreed to commit to purchases of Valtex's products. Valtex was among the first in the industry to introduce this concept, and free-dispensers soon became the industry norm.

\section{Competitive Moves}

In 2007 Valtex began consultative selling - that is, no longer selling products, but analyzing building layouts to design the most efficient hygiene system plans for their customers. But even before that, in 1998, when novel start-up HPE providers tried to sneak into their business, Niko and Tomaž had proposed to them to collaborate with Valtex to operate complicated import procedures on their behalf. By representing a range of Slovenian HPE sellers, Valtex gained some negotiation power with large HPE producers and in consequence was able to negotiate substantial price discounts. In addition, by collaborating with others Valtex could quickly shift among different brands and offer a collaborating partner's brand to a new client if that was preferred.

In 2004, Niko registered the Valtex Economy brand, covering a range of low-priced toilet paper, paper towels, and soaps, the production of which was outsourced to Poland. In 2001, Valtex brought to the market ecohygiene products "Eco Lucart Verde," which were certified with the EU Ecolabel. The purchase price of these products was lower, and their sales steadily grow and accounted for $40 \%$ of all revenues in 2008. For customers, eco-branded products provided considerably lower costs, which was the main reason for shift of customer purchasing habit. For Valtex, these eco-products cannibalized sales of other hygiene products to some extent, and consequently the contribution to revenue growth was smaller than the parallel increase in quantity (volume) sold.

Already in 2001 - as the first Slovenian company in the market - Valtex put ecological products (all certified with EU Ecolabel) in their product range. These products were based on de-inking cellulose, with the commercial name Eco Lucart Verde. In 2010, they added hygiene paper produced with recycled Tetra pak beverage cartons, called Eco Natural Lucart. The fact that these products were sold mainly because of low price and not so much due to environmental credentials cannot be overlooked. In 2007, Valtex also developed a special device for monitoring the consumption of paper towels; however this device has not yet been highly commercialized due to clients' hesitation to apply such a monitoring system.

\section{Organizational Structure and Employees}

With unbroken growth of the company over the period 1994-2008 (see Figure 3) the ambitions of the founders heightened. Complementing organic growth with mergers and acquisitions became an important strategic option. In 2006, Niko was convinced that M\&A was the right strategic move: "Valtex can become the market leader in HPE business in Slovenia. We were growing effortlessly, so I thought "why not start growing also through acquisition?" For that matter, Tomaž and I knew we needed better knowledge of finance, law, and regulation. We two sat down and worked out the organizational design we needed for growth. We designed four functional departments - Sales, Purchasing, Financ and Accounting, and Logistics- and selected the best people to run them. The best sales rep became the sale director. Tomaž took over the purchasing department. The M\&A process was planned to be financed by bank loans."

In 2007-2008, Niko started to formalize the existing organization, group activities, and jobs into functional departments, and introduced two management layers (see Figure 3). This re-organization resulted in a much more formalized and sequenced sales process with CRM information support. Formal performance criteria and goals were established for different stages of the sales funnel; the reward system was tied to the accomplishment of sales goals. However, the formalization of the sales process caused some dissatisfaction and resistance. The friendliness, trustfulness, the sense of collectivity was fading among employees. In the midst of this rising discontent with a new organizational structure, Niko and Tomaž felt lost and confused, unsure whether such a formalized approach to business was the right solution, when the previous business success had been built around flexibility, informality, and intuition. 


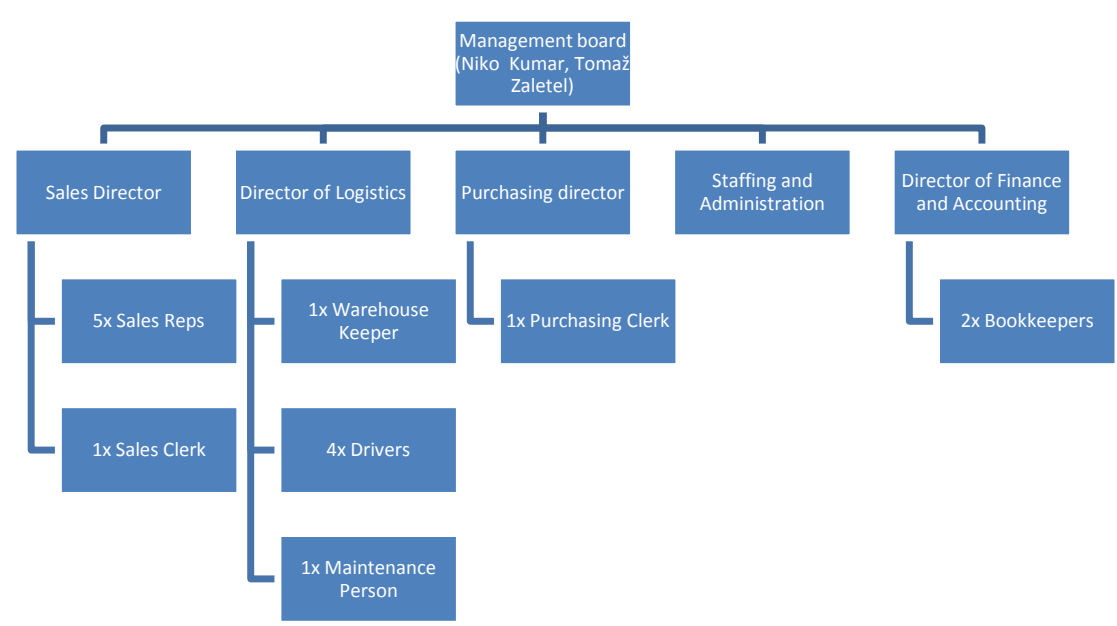

Figure 3: Organizational Structure of Valtex, After Restructuring in 2008

Source: Valtex internal records, 2011

\section{Suppliers}

In 2009, Valtex represented 55 suppliers producing over 1,000 branded products. The main brands of Valtex are Lotus Professional (supplied by Georgia-Pacific, USA) and Lucart (supplied by Lucart Group, Italy). These two brands generated $80 \%$ of total revenues.

\section{Customers}

From 1996-2009, Valtex collaborated with a total of 1,447 different customers. In 2009, Valtex supplied 600 customers. That same year just 91 customers generated $80 \%$ of revenues; the biggest buyer generated $23 \%$ of all sales revenues. Niko and Tomaž were responsible for managing relationships with the key accounts. In the period 2006-2009, customer concentration reduced slightly. In 2006, close to $70 \%$ of Valtex revenues were generated by top 20 key accounts; while in year 2009 around $60 \%$ of revenues came from the top 20 clients. From 2008, onwards the top 20 customers began to buy less. Revenue growth in 2008 was mainly generated by smaller, dispersed accounts. In the period 2000-2009, Valtex invested approximately 400,000 EUR in buyers in a form of free dispensers and other hygiene infrastructure. The biggest investments into clients' infrastructure were made in year 2007 and 2008. Free dispensers in value of 250,000 EUR were assembled in clients' rest rooms in 2007-2008.

\section{Logistics}

An average customer posts an order once per month; with 600 buyers in the portfolio this amounts to 11,900 logistic events per year. Every logistic event involves many employees from different organizational units. Purchasing, sales, and logistics units need to collaborate closely to facilitate the efficiency in logistics. Sales reps split the Slovenian market into five territories, similarly populated with customers. They were responsible for the efficient coverage of the assigned territory, whereby the efficient logistic system played a key role.

\section{Conclusion: Descent of Demand}

In Fall 2009, the average size of orders started to fall, while the frequency of orders rose. Late 2009 beginning of 2010 buyers had cut costs for cleaning services of by reducing the number of days for cleaning service rental from 5 days/week to 2 days/week. This move created considerable pressure on cleaning services companies to cut costs themselves. They in turn pressed HPE providers to reduce prices. At the same time customers began to press VALTEX for price reductions, and many delayed payments. Some new customers postponed the execution of deals already agreed. Selected financial indicators of Valtex in period 1994-2009 are presented in Figure 4. 


\begin{tabular}{|c|c|c|c|c|c|c|}
\hline & 1994 & 1997 & 2000 & 2003 & 2006 & 2009 \\
\hline Tangible fixed assets / Total assets (in \%) & 2.71 & 17.37 & 43.82 & 43.54 & 62.21 & 54.19 \\
\hline Current assets / Total assets (in \%) & 70.07 & 70.83 & 54.06 & 54.31 & 37.51 & 44.08 \\
\hline Capital / Total liabilities (in \%) & 50.93 & 23.33 & 14.19 & 34.74 & 8.39 & 1.59 \\
\hline Debt / Total liabilities (in \%) & 49.07 & 69.18 & 85.4 & 65.26 & 91.59 & 88.22 \\
\hline Current assets / Current liabilities & 1.98 & 1.27 & 0.67 & 0.94 & 0.86 & 0.84 \\
\hline Quick assets / Current liabilities & 1.5 & 0.92 & 0.55 & 0.67 & 0.6 & 0.64 \\
\hline Current asset turnover & n.a. & 3.46 & 3.48 & 3.53 & 3.54 & 3.43 \\
\hline Inventory turnover & 30.96 & 13.01 & 21.43 & 11.67 & 12.94 & 14.67 \\
\hline $\mathrm{A} / \mathrm{R}$ turnover & 18.15 & 5.85 & 4.19 & 5.56 & 5.42 & 4.94 \\
\hline Collection period (in days) & 20.41 & 62.43 & 87.12 & 65.65 & 67.34 & 73.94 \\
\hline Payment period (in days) & 24.64 & 87.17 & 161.32 & 98.84 & 91.53 & 92.88 \\
\hline Return on sales & 2.32 & 3.46 & -4.11 & 2.66 & 3.78 & 2.52 \\
\hline Sales revenues / employee (in EUR) & 87,961 & n.a. & 146,372 & 163,892 & 156,593 & 144,177 \\
\hline Average salary / employee & 100 & n.a. & 601 & 1,048 & 1,134 & 1,615 \\
\hline Value added / employee & 3,958 & n.a. & 6,970 & 26,810 & 29,041 & 33,137 \\
\hline Operating income (EBIT) & 3,098 & 6,979 & $-29,464$ & 33,724 & 73,697 & 70,010 \\
\hline Net income & 1,260 & 3,969 & 419 & 40,108 & 43,105 & 77,300 \\
\hline
\end{tabular}

Figure 4: Selected Financial Indicators of Valtex in Period 1994-2009

Source: Company Valtex, (Financial Reports of Slovenian Companies, 2012)

Competition became more aggressive; stealing clients from competitors through dumping increased. To close deals, some sales reps of competitors employed deceitful tactics, relying on eco-efficiency justifications which held no anchor in reality (labeled also "greenwashing"). There was an increase of other forms of cheating; for example, paper rolls with less paper were supplied to buyers. In the battle for buyers, the Valtex sales team was becoming increasingly stressed, anxious, exhausted, and confused. More and more energy and time was spent managing confrontations and accusations: a negative spiral was at work. Niko was firefighting, and trying to preserve company liquidity, but soon this battle exhausted him too. In response, Niko made several moves: he forced the collection of outstanding accounts receivable, cut inventories to a minimum, delayed accounts payable, simplified the organization structure further by delayering it, centralizing decision-making again, set up a helpdesk for clients, and reduced the number of employees from 21 to 15.

Regardless of these smart moves the fire still raged. Niko, Tomaž, and their employees were pushed well out of their comfort zones; their organizational unity and identity was dissolving rapidly. With that in mind, Niko asked himself and colleagues: "At the Sustainability Academy I have learnt the concept of triple bottom line. Triple bottom line aims to design business in a way to simultaneously meet three goals: be profitable, be attentive to people needs, and preserve the planet. We should think how could we develop more sustainable business in terms of profit, people, and planet? What options do we have?"

For case discussants the following discussion questions are suggested:

- Was building hygiene an attractive business in the period 1994-2007? See Figure 1. Is this an attractive line of business? Profit margins have been relatively low and fluctuating a lot all the time from 2000 onwards, why was Niko at 2008 still so optimistic about the business Valtex was in? Perform five forces analysis of the industry value chain.

- Where does Valtex add value in this value chain? What are Valtex's critical value adding activities? How distinctive is Valtex from competitors? If Valtex is analyzed from TBL (triple bottom line perspective), how well does Valtex do in terms of people and planet aspects of TBL? Is Valtex more planet friendly than competitors?

- $\quad$ Perform a brain-storming workshop and think how could critical value adding activities be restructured to make Valtex operations more distinctive from competitors, more profitable, more environmentally, and more people (employee) friendly?

- Come up with specific goals and precise measures scheme for each aspect of TBL. How would you measure the profit aspect of TBL? How would you measure the people aspect of TBL? How would you measure the planet aspect of TBL?

- If pursuing only the profit goals, how would you re-design Valtex critical value adding activities? 
- If pursuing only the people goals, how would you re-design Valtex critical value adding activities?

- If pursuing only the planet goals, how would you re-design Valtex critical value adding activities?

$\circ$ Outline main tradeoffs between each proposal of design of Valtex activities. What does this trade-off tell us? What changes in activities should Valtex implement?

\section{ACKNOWLEDGEMENTS}

The author thanks Aleš Planina, whose assistance in writing and data collection was indispensable in the process of preparing this case. In addition, the author also thanks Niko Kumar, CEO of Valtex for his willingness to disclose the company and allow using its business dilemmas for teaching purposes. Last, but not least, the author also thanks all participants of the Academy on Sustainability at the Faculty of Economics, University of Ljubljana in Fall 2012 for their suggestions and opinion regarding the Valtex case.

\section{AUTHOR INFORMATION}

Melita Balas Rant is an Assistant professor at Faculty of Economics, University of Ljubljana and director of open and in-company executive programs at the Centre for Business Excellence of Faculty of Economics. She teaches courses on organizational design, organizational change, leadership and change. She is the former director of Executive MBA programs at IEDC-Bled School of Management and research coordinator at CEEMAN. Her research interests are psychology of strategic leadership, leadership, social capital, organizational inertia, and business model design. In this area she has published several scientific and professional articles and cases. E-mail: melita.balas.rant@ef.uni-lj.si

\section{REFERENCES}

1. Blum, L. (1996). The production of bleached kraft pulp. Retrieved August 20, 2012 from http://www.rfu.org/cacw/basic2KraftPulp.htm

2. Brandenburger, A. M., \& Stuart, H. (1996). Value-based business strategy. Journal of Economics \& Management Strategy, 5(1), 5-24.

3. $\quad$ Elkington, J. (2002). Cannibals with forks. Oxford: Capstone Publishing Limited.

4. Financial Reports of Slovenian Companies. (2012). Retrieved August 2012 from http://www.gvin.com/

5. $\quad$ Porter, M. E. (1985). Competitive advantage. New York: Free Press.

6. Public Reporting System of Commission for the Prevention of Corruption. (2012). Supervizor. Retrieved August 20, 2012 from http://supervizor.kpk-rs.si/

7. Tripsas, M., \& Gavetti, G. (2000). Capabilities, cognition, and inertia: Evidence from digital imaging. Strategic Management Journal, 21(10/11), 1147-1161.

8. Valtex Company Profile. (2012). Retrieved September, 26 2012from http://www.valtex.si/ 